\title{
Eluxadoline in the treatment of diarrhea- predominant irritable bowel syndrome
}

This article was published in the following Dove Press journal:

Drug Design, Development and Therapy

26 September 2017

Number of times this article has been viewed

\section{Ayșe Elif Özdener \\ Anastasia Rivkin}

School of Pharmacy and Health Sciences, Fairleigh Dickinson University, Florham Park, NJ, USA
Correspondence: Ayșe Elif Özdener School of Pharmacy and Health Sciences, Fairleigh Dickinson University, 230 Park Ave, M-SPI-0I, Florham Park, NJ 07932, USA

$\mathrm{Tel}+$ I 97344382 II

Email eozdener@fdu.edu

\begin{abstract}
Eluxadoline is a novel drug approved for the management of diarrhea predominant irritable bowel syndrome (IBS-D). It has unique pharmacology and works on three different opioid receptors. Several Phase II and III clinical trials have demonstrated eluxadoline's efficacy in reducing symptoms related to IBS-D. Clinical trial results and postmarketing reports show a risk of pancreatitis in patients without a gallbladder or those abusing alcohol. This review article will include information on clinical trial results related to IBS-D management as well as eluxadoline's limitations.
\end{abstract}

Keywords: IBS-D, eluxadoline, diarrhea, gastrointestinal, Viberzi

\section{Introduction}

Irritable bowel syndrome (IBS) is a common gastrointestinal (GI) ailment presenting with abdominal pain, discomfort, and bloating, along with change in bowel habits. Organic causes of the symptoms (eg, inflammatory bowel disease), as well as alarming features (eg, weight loss), need to be evaluated, if present, prior to making a definitive diagnosis of IBS. ${ }^{1}$ IBS is the most commonly diagnosed gastrointestinal disease. ${ }^{2}$ It is estimated that IBS affects approximately $11 \%$ of the world population. ${ }^{3}$

IBS can be further divided into three subtypes depending on the predominant bowel symptom: IBS diarrhea-predominant (IBS-D), IBS constipation-predominant (IBS-C), and IBS mixed-symptoms (IBS-M). In the USA, IBS-M is the most prevalent subtype (44\%), followed by IBS-C (28\%), and IBS-D (26\%). ${ }^{1,4}$

This article provides an overview of current management strategies for IBS-D, reviews the evidence supporting the use of the novel agent eluxadoline in the management of IBS-D, and describes eluxadoline's potential place in therapy for IBS-D.

\section{Current and emerging treatment options}

Currently, it is thought that multiple factors contribute to the pathophysiology of IBS. These factors include visceral hypersensitivity, altered intestinal motility, and psychosocial dysfunction. Additional factors may include bile acid malabsorption, changes in fecal microflora, small intestinal bacterial overgrowth (SIBO), enteritis triggered by gastrointestinal infection, and abnormal gut immune activation and mucosal inflammation with increased numbers of lymphocytes, mast cells, and inflammatory cytokines. ${ }^{5,6}$ Other factors, such as food intolerance/allergy and genetic predisposition, have been implicated, but remain controversial.

The most recent American College of Gastroenterology (ACG) monograph summarizing evidence-based recommendations for management of IBS was published in 2014. ${ }^{7}$ American Gastroenterological Association (AGA) Institute guidelines focusing 
on pharmacological therapies for IBS were published in the same year. ${ }^{8}$

Based on review of these guidelines, it is clear that while many agents can be of clinical benefit to a subset of patients with IBS-D, many of the traditionally used pharmacological treatments do not have strong clinical trial evidence to unequivocally support their use. In addition, there is no widely accepted step-wise treatment approach to guide IBS-D management; once the diagnosis of IBS-D is made, the goal is to alleviate the most bothersome symptoms. ${ }^{9}$

Non-pharmacologic options are important and can provide relief to some patients. These options should be tried first line, and may consist of dietary modifications, regular exercise, and improved sleep hygiene..$^{9,10}$

Current pharmacological treatments for IBS-D include pre- and probiotics, antidiarrheal medications, antispasmodics, antidepressants, antibiotics, and 5-hydroxytryptophan 3 $\left(5-\mathrm{HT}_{3}\right)$ receptor antagonists.

Due to the abundance of various preparations of preand probiotics and lack of quality evidence to support their use, current ACG and AGA guidelines do not provide definitive recommendations regarding their place in IBS-D management.

Loperamide (Imodium-AD) is an effective antidiarrheal agent with limited evidence to support its use in IBS-D. Loperamide inhibits peristalsis by acting as an agonist at the intestinal opioid receptors, decreases secretory activity, and decreases stool volume. The main limitation of loperamide is lack of evidence to support its efficacy related to global IBS-D symptoms; however, it is an effective agent to decrease frequency and improve consistency of the stool. Based on clinical experience, loperamide can be used in some patients as an adjunctive treatment to other IBS therapies. ${ }^{8}$

Antispasmodics work by either their anticholinergic/ antimuscarinic properties (eg, dicyclomine/Bentyl), or by calcium channel-blocking properties (eg, peppermint oil). Antispasmodics have been shown to provide improvement in IBS-D symptoms (number needed to treat $[\mathrm{NNT}]=5$ ). These medications are most effective if taken before eating as they decrease abdominal pain and diarrheal episodes that occur in response to a meal. Anticholinergic side effects, such as dry mouth, constipation, blurred vision, and palpitations, may occur with higher doses. The main adverse effect of peppermint oil is gastroesophageal reflux due to the relaxation of lower esophageal sphincter. A new microsphere formulation of peppermint oil (IBgard), classified as a medical food, is designed to deliver ultra-purified peppermint oil to the small intestine. This formulation is more effective than placebo in relieving total IBS symptoms scores. ${ }^{11}$
Antidepressants increase synaptic concentration of neurotransmitters, for example, norepinephrine and serotonin; this results in mood-altering and analgesic properties beneficial to IBS-D patients. Antidepressants, as a class, provide improvement in global IBS symptoms over placebo $(\mathrm{NNT}=4)$. Tricyclic antidepressants (TCAs), such as desipramine, provide modest relief of global IBS symptoms. TCAs also block muscarinic, acetylcholine, and histamine receptors and can increase gastrointestinal transit time, which is useful in patients with IBS-D. TCA limitations include potential to induce cardiac arrhythmias, as well as anticholinergic side effects. These agents should be used with caution in young and old patients: US labeling includes a warning regarding an increased risk of suicidal ideation and behavior in children, adolescents, and young adults. TCAs also increase confusion and risk of falls in the elderly, and should be avoided in this population. ${ }^{12}$

Data on efficacy of selective serotonin reuptake inhibitors (SSRIs), such as paroxetine (Paxil), are conflicting. ${ }^{13,14}$ ACG guidelines state that use of SSRIs was associated with reduction in IBS symptoms, but AGA Institute guidelines advise against using SSRIs in patients with IBS. Given these controversial recommendations, SSRIs may be used in a patient who has both IBS and depression as comorbidities. In clinical practice, SSRIs are most frequently used in patients with IBS-C because they tend to decrease gastrointestinal transit time. Incidence of serious adverse effects with SSRIs is low, with the main problem being sexual dysfunction.

Rifaximin is a minimally absorbed antibacterial agent. Rifaximin works by impairing bacterial protein synthesis, and is active against many gram-positive, gram-negative, and protozoal organisms. Its mechanism in improving IBS-D symptoms is unclear; likely, decreasing SIBO plays a role to some extent. ${ }^{15}$ Rifaximin is moderately effective and provides adequate relief of global IBS symptoms (NNT $=11)$. It is well-tolerated; the main concerns include potential to induce resistance with repeated courses.

Alosetron is the only $5-\mathrm{HT}_{3}$ receptor antagonist approved in the USA for IBS-D treatment. The 5- $\mathrm{HT}_{3}$ receptor blockade results in modulation of visceral pain, decrease in gastrointestinal secretion, and slower colonic transit. The drug is effective in women with IBS-D, with NNT $=8 .^{7,16}$ Alosetron is recommended to be used to manage patients with chronic symptoms ( $>6$-month duration) who have failed to respond to conventional therapies. However, due to $0.1 \%$ of patients developing ischemic colitis, alosetron is subject to the most extensive US Food and Drug Administration (FDA) risk evaluation and mitigation strategy regulation (REMS) elements to assure safe use (ETASU). ${ }^{17}$ This element require 
that only physicians who have completed an FDA-approved training program can prescribe it, limiting patient access to assure safety. The main adverse effect of alosetron is constipation.

Ondansetron, a $5 \mathrm{HT}_{3}$ antagonist used to manage nausea and vomiting, has recently been shown to improve stool consistency, decrease urgency and stool frequency, and improve bloating in patients with IBS-D. However, pain scores were not significantly improved. ${ }^{18}$ Neither ACG nor AGA guidelines mention ondansetron in their treatment recommendations; more data are needed before this agent can be considered for IBS-D management.

\section{Material and methods}

Relevant clinical trials were identified by using the search term "eluxadoline" in Medline and search terms "eluxadoline," "eluxadoline in IBS-D," and "eluxadoline AND IBS-D” in PubMed. There were 45 articles identified in Medline and 46 in PubMed, seven of which were randomized controlled trials. All of those articles have been included in this review. Case reports, review articles, systematic reviews, and articles unrelated to the use of eluxadoline for IBS-D were excluded from this review article.

\section{Review of pharmacology, mechanism of action, and pharmacokinetics of eluxadoline}

Eluxadoline is a mu-opioid receptor agonist, delta-opioid receptor antagonist, and kappa-opioid receptor agonist indicated for the management of symptoms of IBS-D in adult patients. It exhibits a mechanism of action in the gut by slowing gastrointestinal (GI) motility and decreasing visceral hypersensitivity, thereby reducing symptoms of loose stools and abdominal pain that are predominant in IBS-D. Eluxadoline is available as 75 and $100 \mathrm{mg}$ tablets. The recommended dose in adults is $100 \mathrm{mg}$ twice daily with food. A $75 \mathrm{mg}$ twice-daily dose should be used in patients who are unable to tolerate the $100 \mathrm{mg}$ dose, those who receive concomitant organic anion-transporting polypeptide 1B1 (OATP1B1) inhibitors, or patients with preexisting mild or moderate hepatic impairment. ${ }^{19}$

Oral administration of $100 \mathrm{mg}$ of eluxadoline in healthy patients yields a $\mathrm{C}_{\max }$ of 2-4 $\mathrm{ng} / \mathrm{mL}$ and an area under the concentration-time curve (AUC) of 12-22 ng*h/mL. When eluxadoline is administered with a high-fat meal containing $800-1,000$ calories ( $50 \%$ of calories derived from fat), the $\mathrm{C}_{\max }$ and AUC decrease by $50 \%$ and $60 \%$, respectively. The bioavailability of eluxadoline is unknown. When administered under fed conditions, the median $\mathrm{T}_{\max }$ is 1.5 hours.
Under fasting conditions, the median $\mathrm{T}_{\max }$ is 2 hours. Eluxadoline is $81 \%$ bound to plasma proteins. Its elimination half-life ranges from 3.7 to 6 hours. There is no accumulation of drug when administered twice daily. The exact mechanism behind the metabolism of eluxadoline is currently unknown. Eluxadoline is mostly excreted in the feces. Less than $1 \%$ of eluxadoline was recovered in the urine 192 hours after the administration of a $300 \mathrm{mg}$ dose. The administration of $100 \mathrm{mg}$ of eluxadoline increased plasma levels of drug by sixfold, four-fold, and 16-fold in patients with mild, moderate, and severe hepatic impairment, respectively. ${ }^{19}$

In vitro studies of eluxadoline show that it is a substrate for organic anion transporter 3 (OAT3), OATP1B1, bile salt export pump (BSEP), and multidrug resistance protein 2 (MRP2) and an inhibitor of OATP1B1. There is insufficient data to show that eluxadoline is an inhibitor of most CYP450 enzymes or P-glycoprotein in the gut. ${ }^{19,20}$ In vitro studies show that eluxadoline may inhibit CYP2E1, but the clinical significance of this inhibition is unknown. There are no established drug-drug interactions between eluxadoline and oral contraceptives. Concomitant administration of a single dose of eluxadoline $100 \mathrm{mg}$ and cyclosporine $600 \mathrm{mg}$ caused a 4.4-fold and 6.2-fold increase in the $\mathrm{AUC}$ and $\mathrm{C}_{\text {max }}$ of eluxadoline, respectively. ${ }^{19}$ This is because cyclosporine is an OATP1B1 and MRP2 inhibitor. ${ }^{20}$ In vivo studies also show an interaction with probenecid and rosuvastatin. ${ }^{19}$ Probenecid is an MRP2 and OAT3 inhibitor and an MRP2 substrate. ${ }^{20}$ A single dose of eluxadoline $100 \mathrm{mg}$ and probenecid $500 \mathrm{mg}$ taken concomitantly yielded $35 \%$ and $31 \%$ increases in eluxadoline $\mathrm{AUC}$ and $\mathrm{C}_{\max }$, respectively. When a single dose of rosuvastatin $20 \mathrm{mg}$ was given with multiple doses of eluxadoline $100 \mathrm{mg}$, rosuvastatin $\mathrm{AUC}$ and $\mathrm{C}_{\max }$ increased by $40 \%$ and $18 \%$, respectively. ${ }^{19}$

Eluxadoline is a controlled substance schedule IV drug due to its mu-opioid receptor agonist action and results from randomized controlled trials that showed a small percentage of patients experiencing euphoria and feeling drunk after a dose of eluxadoline. ${ }^{19,21,22}$ This will be further discussed under the safety/abuse potential subsection of this article.

\section{Efficacy and safety of eluxadoline Efficacy}

A Phase II, randomized, double-blinded, placebo-controlled trial (IBS-2001) studied the efficacy of eluxadoline in $5 \mathrm{mg}$ $(\mathrm{n}=105), 25 \mathrm{mg}(\mathrm{n}=167), 100 \mathrm{mg}(\mathrm{n}=163)$, and $200 \mathrm{mg}$ $(n=160)$ twice-daily doses compared to placebo $(n=159)$ for patients with IBS-D. The primary endpoint was the percent of patients who achieved clinical response at Week 4. Clinical response was defined as $\geq 30 \%$ self-reported decrease 
in mean daily worst abdominal pain (WAP) scores from baseline and a daily Bristol Stool Scale score of 3-4 on at least $66 \%$ of the daily diary entries within that week (score of $1=$ hard stools, score of $7=$ watery, liquid stools). Interestingly, subjects randomized to the 25- and 200-mg arms had a greater response rate compared to placebo (12\% vs $5.7 \%$, $p=0.041 ; 13.5 \%$ vs $5.7 \%, p=0.015)$. The response rate in the 100-mg dose arm showed a non-significant trend toward improvement at Week 4 ( $p=0.09$ ). At Week 12, the 100-mg arm did show a statistically significant improvement over placebo in the primary endpoint (20.2\% vs $11.3 \%, p=0.03)$. The 25- and 200-mg treatment arms were not found to have a statistically significant difference over placebo at Week 12 . There were no significant improvements in any of the four arms in the WAP-only analysis at Week 4. There was a trend toward improvement in WAP score at Week 12 in the 100-mg arm compared to placebo, but it did not reach statistical significance $(49.1 \%$ vs $39.6 \%, p=0.087)$. There was a significant difference in stool consistency response rates in the 25- and 200-mg arms compared to placebo at Week 4 (16.8\% vs $8.2 \%, p=0.016 ; 18.1 \%$ vs $8.2 \%, p=0.008$, respectively). A non-significant trend toward improvement in stool consistency response rate was noted in the 100-mg arm ( $14.1 \%$ vs $8.2 \%, p=0.083$ ). Of note, patients were allowed to use loperamide and acetaminophen during the trial for relief of symptoms, but the use of these medications was not found to have an impact on WAP, stool consistency, and the composite score. Loperamide use averaged at $<1$ dose per week across each treatment arm. Although not specified, acetaminophen use was reported less frequently than loperamide; therefore, rescue medication use is unlikely to impact the results of this study. ${ }^{23}$

Two Phase III, double-blind, placebo-controlled, multicenter trials led to the FDA approval of eluxadoline-IBS-3001 and 3002. Investigators enrolled 1,232 subjects in IBS-3001 and 1,146 in IBS-3002. Both IBS-3001 and 3002 aimed to assess the efficacy of eluxadoline compared to placebo in the first 26 weeks of the trial. Where these two trials differed is in the remainder of the study period. Subjects in IBS-3001 continued for an additional 26 weeks and were on treatment only. This part of the trial was designed to evaluate the safety parameters of eluxadoline. After a total of 52 weeks, subjects were followed for two additional weeks as posttreatment follow-up. IBS-3002 was a shorter trial. In addition to the first 26 weeks, subjects were given placebo only for 4 more weeks to assess whether they experienced rebound worsening symptoms of IBS-D. The treatment arms for both studies were eluxadoline $75 \mathrm{mg}$, eluxadoline $100 \mathrm{mg}$, or placebo - all given twice daily. The primary endpoint of both studies was the percentage of patients who achieved the composite endpoint, defined as simultaneous improvement in abdominal pain and stool consistency. Improvement of abdominal pain was defined as at least a $30 \%$ reduction from baseline in patients' daily average score of abdominal pain for at least $50 \%$ of days in the trial. Stool consistency score of less than 5 (scale 1-7; a score of 1 indicates hard stools, whereas 7 indicates watery diarrhea) had to occur on the same day as relief of abdominal pain to be included in the composite endpoint evaluation. ${ }^{24}$

In both studies, patients randomized to receive eluxadoline 75 or $100 \mathrm{mg}$ had a significantly greater response in the primary endpoint compared to placebo during the initial 12 weeks. In IBS-3001, 23.9\% of patients in the $75-\mathrm{mg}$ arm, $25.1 \%$ in the $100-\mathrm{mg}$ arm, and $17.1 \%$ in the placebo arm showed reduction in symptoms $(p=0.01)$. The NNT for the 75- and 100-mg arms was 15 and 13, respectively. In IBS-3002, subjects in the eluxadoline 75-mg, 100-mg, and placebo arms had a reduction in symptoms by $28.9 \%, 29.6 \%$, and $16.2 \%$, respectively $(p<0.001)$. The NNT for both arms in IBS-3002 was $8 .^{24}$

From weeks 1 to 26, only the 100-mg arm performed significantly better than placebo in the primary endpoint $(29.3 \%$ vs $19 \%, p<0.001)$ in IBS-3001. Results were different in IBS-3002, where both the 75- and 100-mg arms performed significantly better than placebo in the primary endpoint (30.4\% and $32.7 \%$ vs $20.2 \%$, respectively; $p=0.0001$ for $75 \mathrm{mg}$ vs placebo; $p<0.001$ for $100 \mathrm{mg}$ vs placebo). ${ }^{24}$

Pooled data from secondary endpoints from both trials showed that subjects in the 75- and 100-mg arms had greater improvement in stool consistency ( 75 and $100 \mathrm{mg}$ vs placebo: $p<0.001$ ), frequency ( $75 \mathrm{mg}$ vs placebo: $p=0.002 ; 100 \mathrm{mg}$ vs placebo: $p<0.001$ ), and urgency ( $75 \mathrm{mg}$ and $100 \mathrm{mg}$ vs placebo: $p<0.001)$. There was no difference among the groups in incontinence. Symptoms of bloating were less severe in patients receiving $100 \mathrm{mg}$ vs placebo $(p=0.003)$. No significant difference was found among the arms in the percent of patients who reported improvement of $30 \%$ or more in the score of worst abdominal pain. It was only when a stricter reduction in score ( $\geq 40 \%$ and $\geq 50 \%$ ) was analyzed that a difference was found in the 100-mg arm compared to placebo (40\%: $p=0.003 ; 50 \%: p=0.01)$. No worsening symptoms of IBS-D or withdrawal symptoms were reported during the 2-week posttreatment follow-up period in IBS-3001 or the 4-week, placebo-only period in IBS-3002. ${ }^{24}$

Of note, the use of antidepressants was not an exclusion criterion in the study design. Subjects were allowed to use 
antidepressants throughout the trial as long as they were on a stable dose for $>12$ weeks at enrollment. ${ }^{24}$ The number of subjects who used antidepressants and the class of antidepressants used within each arm was not mentioned. Subjects using TCAs may have had more favorable results because this class of antidepressants can also be used to manage IBS-D symptoms. An additional limitation was the relatively short study duration (26 weeks) to assess eluxadoline efficacy.

A pre-specified, prospective, subgroup analysis examined eluxadoline efficacy in patients who reported prior loperamide use in the IBS-3001 and 3002 studies. Subjects were stratified to loperamide responders and non-responders. The eluxadoline composite responder rate was similar between the loperamide responders and non-responders. Among loperamide responders, a greater portion of subjects in the eluxadoline 75- and 100-mg arms were composite responders than in the placebo arm, although the difference between the eluxadoline 75-mg arm and placebo did not reach statistical significance ( $p=0.006$ for eluxadoline $100 \mathrm{mg}$ vs placebo). Among the loperamide non-responders, patients in the eluxadoline 75- and 100-mg arm had a larger portion of composite responders compared to placebo ( $p=0.001$ and $p<0.001$, respectively). A greater proportion of patients reporting inadequate symptom control with prior loperamide use had improved stool consistency (75 mg, $p=0.002 ; 100 \mathrm{mg}$, $p<0.001$ vs placebo). Similar results were seen in patients who reported adequate relief of symptoms with prior loperamide use ( $75 \mathrm{mg}, p=0.037 ; 100 \mathrm{mg}, p=0.012$ vs placebo). Overall, stool consistency responder rates were higher in subjects who reported adequate symptom relief with prior loperamide use, compared to those who reported inadequate relief. Subjects who experienced inadequate response to prior loperamide use had lower rates of abdominal pain in the eluxadoline 75-mg arm compared to placebo $(p=0.01)$. There was no statistically significant difference between eluxadoline $100 \mathrm{mg}$ and placebo, although the eluxadoline 100-mg arm had lower rates of subjects with abdominal pain. The subgroup analysis also showed that the use of loperamide during the study did not affect eluxadoline composite responder rates. An ongoing study investigating efficacy of eluxadoline in IBS-D patients who had inadequate symptom control with loperamide use will provide additional information on whether eluxadoline offers relief to this subset of patients. ${ }^{25}$

A post hoc analysis of IBS-3001 and IBS-3002 compared eluxadoline responder rates over the first month of treatment versus responder rates over 6 months in subjects randomized to either the eluxadoline or placebo arm. Over
1 month, $22.8 \%, 24.6 \%$, and $12.5 \%$ of subjects were composite responders in the $75-\mathrm{mg}, 100-\mathrm{mg}$, and placebo arms, respectively. Within the 1 -month responders, $81.5 \%$ and $77.8 \%$ continued to show a response over months $1-3$ in the 75 and 100-mg arms, respectively. Within 1-month responders, $73.9 \%$ and $70.7 \%$ continued to show a response over months $1-6$ in the 75- and 100-mg arms, respectively. Among the number of nonresponders within 1 month of therapy, less than $20 \%$ of subjects showed a response in months $1-3$ and months 1-6. Although the percentage of patients who are responders at the 1-month mark is not very high, those who do respond tend to continue to respond to eluxadoline in the future. On the other hand, the likelihood of responding to eluxadoline past the 1-month mark if response was not seen by 1 month is low. ${ }^{26}$

Table 1 contains a summary of Phase II and III clinical trials mentioned in this section.

\section{Safety}

\section{$\mathrm{Gl}$ and Central Nervous System (CNS) adverse effects}

In the Phase II trial, adverse events were similar between the 5-, 25-, and 100-mg arms. Specific results from the 5-mg and 25-mg eluxadoline arms have been excluded as these doses are unavailable and not used in practice. Subjects randomized to receive $200 \mathrm{mg}$ twice daily reported higher rates of severe adverse events, discontinuation due to adverse events, and non-serious GI and CNS events. The most commonly reported GI adverse events among patients who took eluxadoline were nausea, vomiting, abdominal pain, and constipation. Abdominal pain (100 mg: 2\%; $200 \mathrm{mg}$ : 8\%; placebo: 2\%), dizziness (100 mg: 3\%; $200 \mathrm{mg}$ : 6\%; placebo: 3\%), vomiting (100 mg: 4\%; $200 \mathrm{mg}$ : 7\%; placebo: 1\%), and nausea (100 mg: 5\%; $200 \mathrm{mg}$ : 10\%; placebo: 4\%) were seen at higher rates in the $200-\mathrm{mg}$ arm compared to other arms. Higher rates of constipation were seen in the 100-mg arm compared to other arms (100 mg: 6\%; $200 \mathrm{mg}$ : 3\%; placebo: $3 \%)^{23}$

The most common adverse events reported in two Phase III trials were nausea, constipation, and abdominal pain. Discontinuation rates due to constipation were very low $-1.1 \%, 1.7 \%$, and $0.2 \%$ in the $75-\mathrm{mg}, 100-\mathrm{mg}$, and placebo arms, respectively. The rate of discontinuation due to nausea was $0.6 \%, 0 \%$, and $0.5 \%$ in the $75-\mathrm{mg}, 100-\mathrm{mg}$, and placebo arms, respectively. ${ }^{24}$

A subgroup analysis of Phase III studies focusing on adverse event rates in patients who previously reported inadequate relief of symptoms with prior loperamide use 


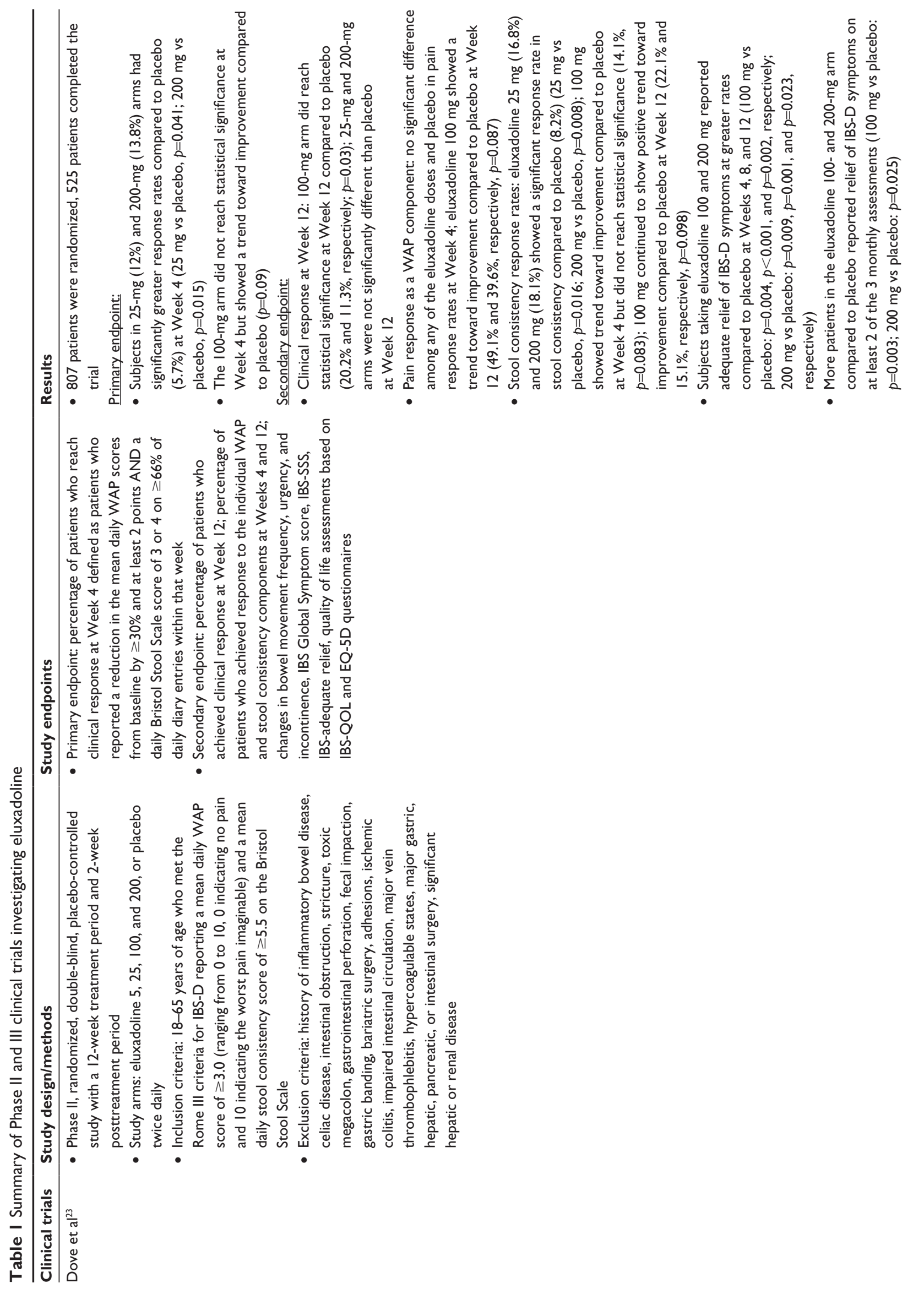




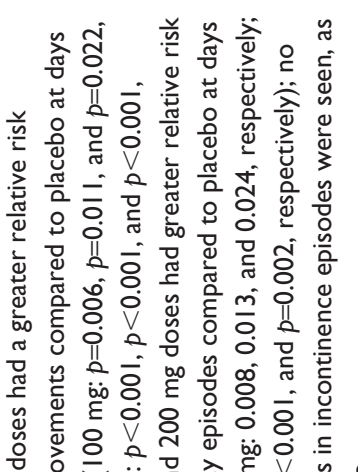

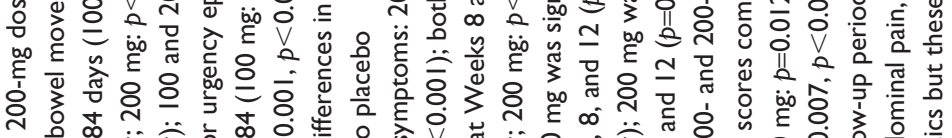

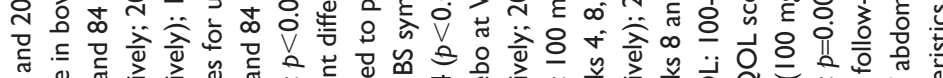

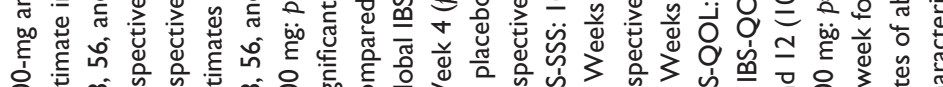

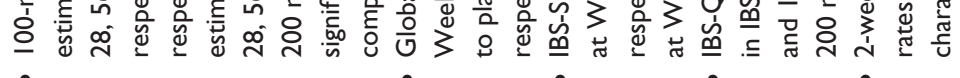

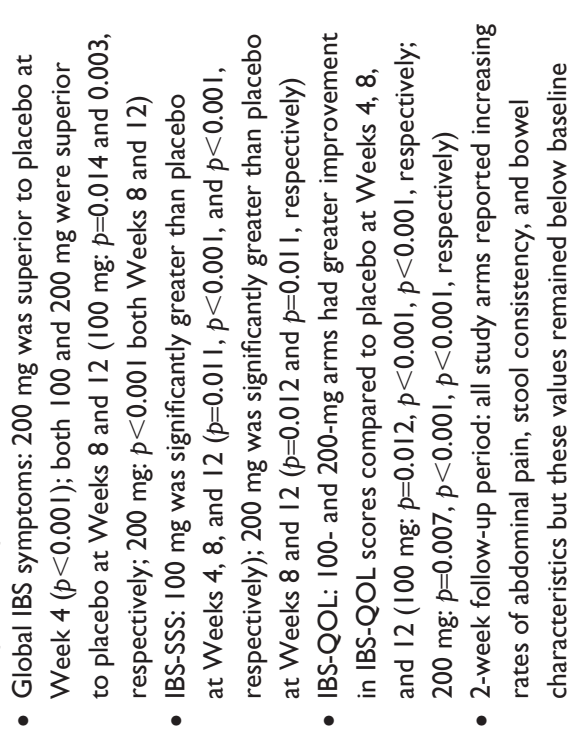

(1)

\section{$\frac{10}{5}$}

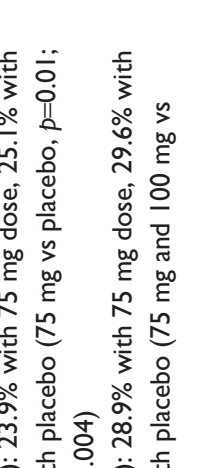

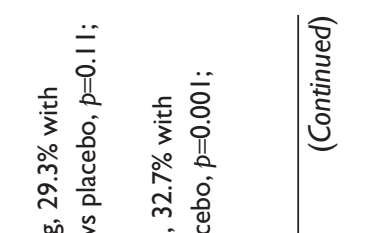

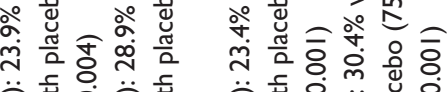

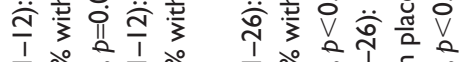

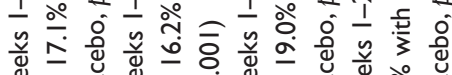

उ.

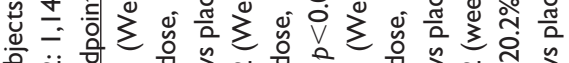

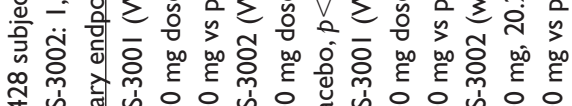

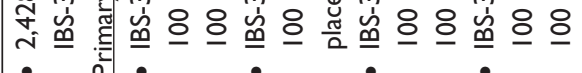

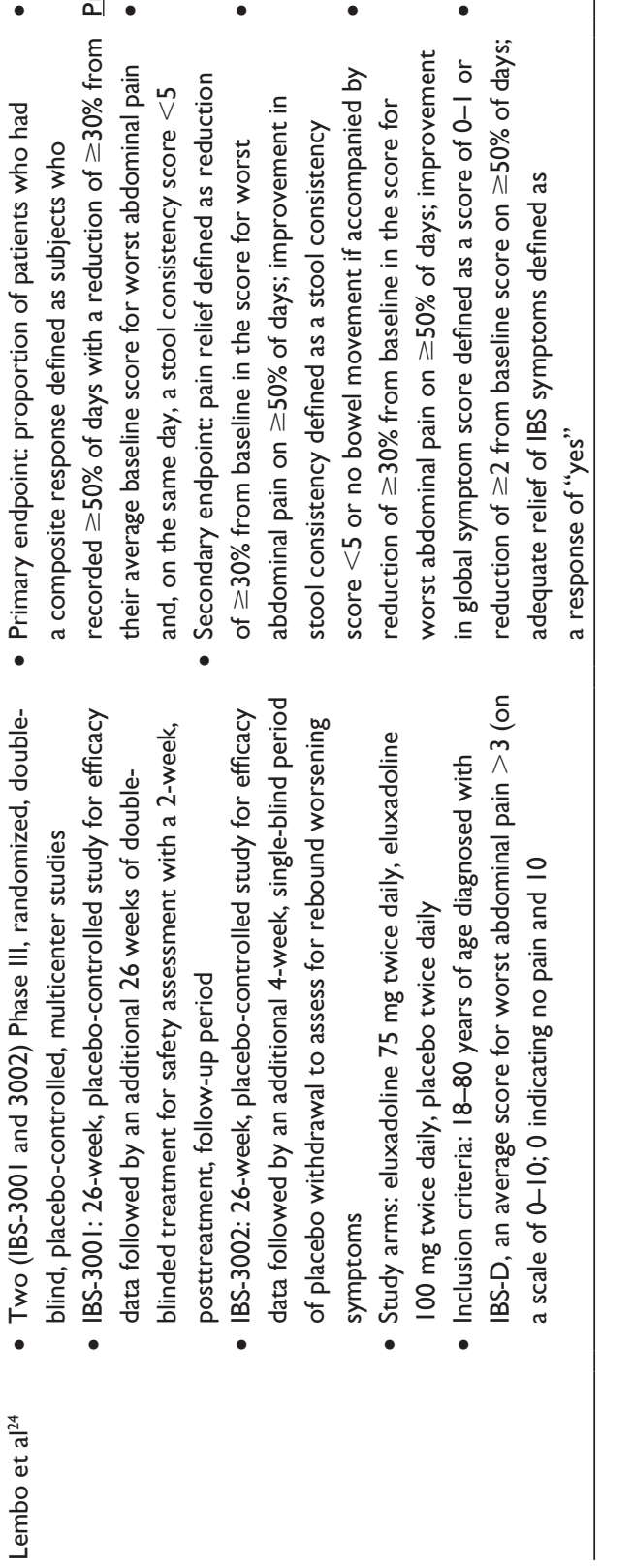




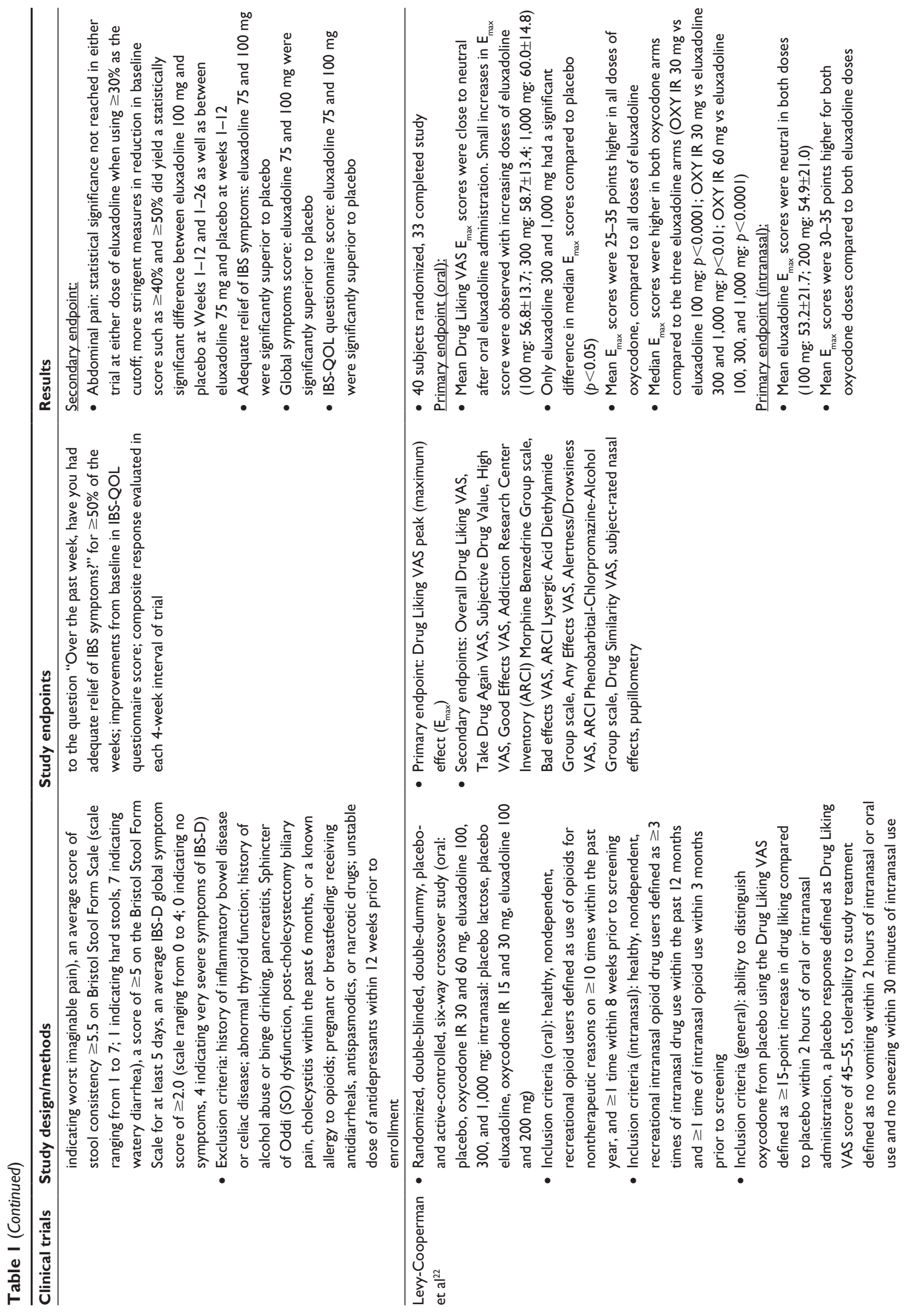



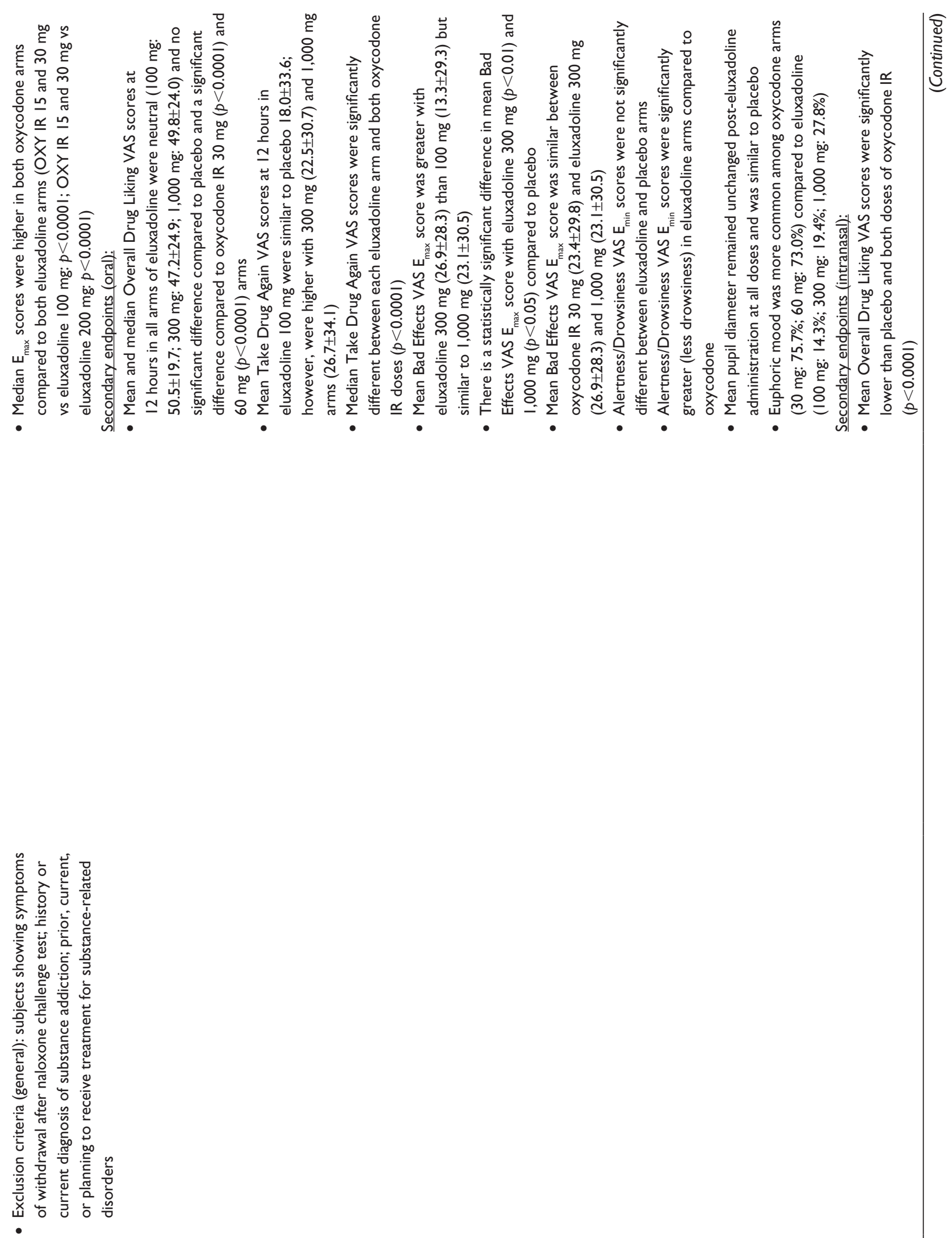


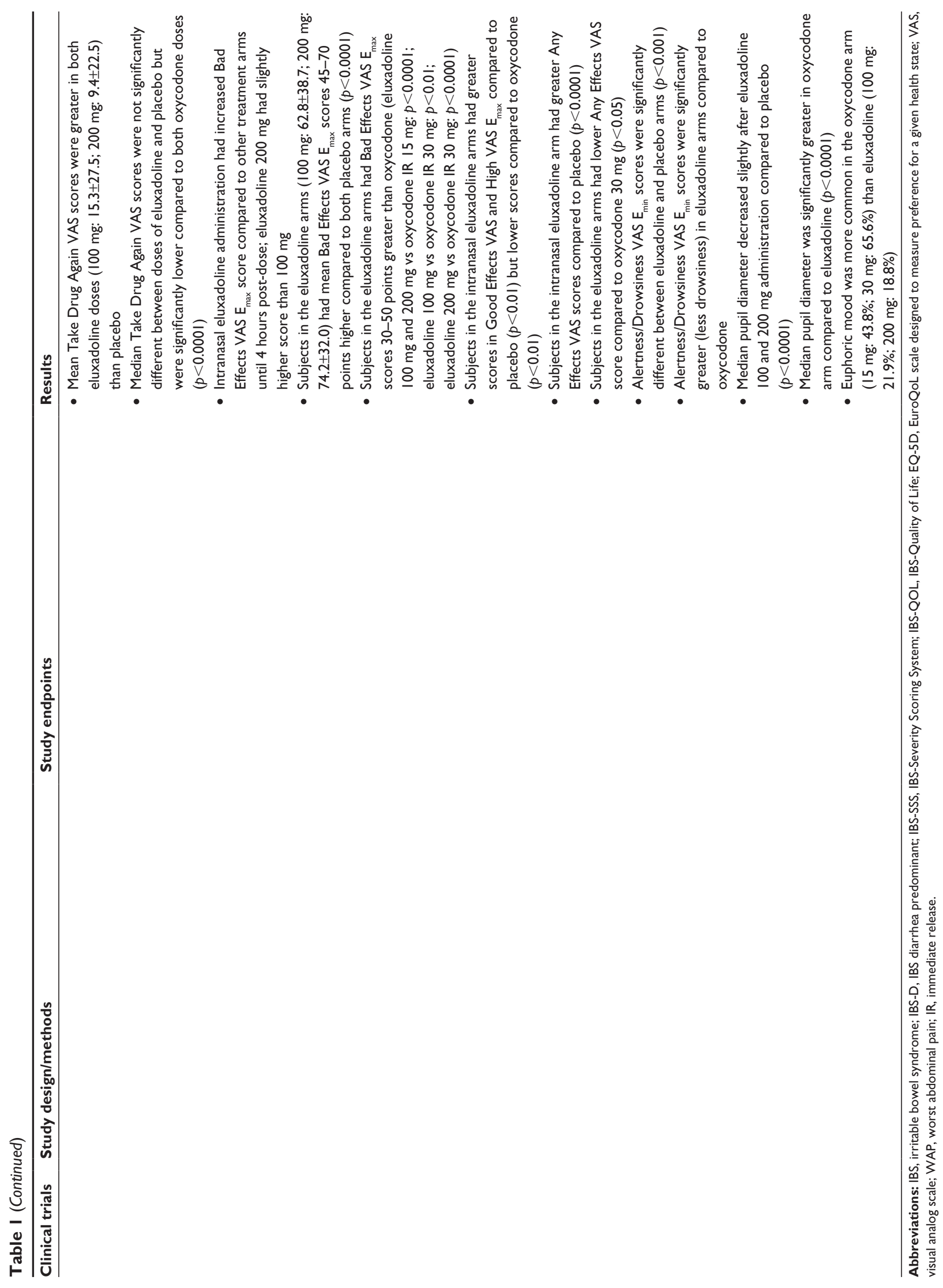


was conducted. The rate of adverse events was similar in both eluxadoline arms. The most common adverse events reported were nausea, abdominal pain, constipation, and headache. Subjects in the eluxadoline 100-mg arm experienced more constipation that those in the eluxadoline 75-mg arm. There was no definite association between the timing of loperamide rescue dose and report of an adverse event. ${ }^{25}$

A separate safety analysis of pooled data from subjects in Phase II and III trials (IBS-2001, 3001, and 3002) showed that the most commonly reported adverse events $(\geq 2 \%$ in any arm) among patients assigned to an eluxadoline arm were constipation, nausea, vomiting, upper respiratory tract infection, abdominal pain, and headache. These adverse events occurred more frequently in the eluxadoline arms than in the placebo arm. The most commonly reported reason for treatment discontinuation within the eluxadoline arms was constipation and abdominal pain; however, the frequency of these occurrences was low (constipation: 1.1\% in eluxadoline $75 \mathrm{mg}, 1.5 \%$ in eluxadoline $100 \mathrm{mg}$; abdominal pain: 1.1\% in both eluxadoline arms). ${ }^{27}$

\section{Pancreatitis}

Like other opioids, eluxadoline can cause Sphincter of Oddi (SO) spasms. This causes pancreatic enzymes and bile to back up to the pancreas, which can lead to pancreatitis. Patients without a gallbladder are especially at risk since the gallbladder stores excess bile. ${ }^{28}$ Pancreatitis was seen in a small number of subjects in clinical trials.

Rates of serious adverse events (SAEs) in a subgroup analysis of Phase II and III trials (IBS-2001, 3001, and 3002) were higher in the eluxadoline arms than placebo $(4.2 \%$ in eluxadoline $75 \mathrm{mg}, 4.0 \%$ in eluxadoline $100 \mathrm{mg}, 2.6 \%$ in placebo). Pancreatitis was the most commonly reported SAE in both eluxadoline arms $(3[0.4 \%]$ and $4[0.4 \%]$ patients in eluxadoline 75 and $100 \mathrm{mg}$, respectively); $0.2 \%$ of pancreatitis cases occurred within the first 2 weeks of initiating eluxadoline $100 \mathrm{mg}$. All cases of pancreatitis were mild in severity, based on Atlanta criteria. ${ }^{29}$ Only six of these seven events were confirmed to be pancreatitis. One case of pancreatitis was related to SO spasm, while three were associated with excessive alcohol intake. In total, there were five patients in both eluxadoline arms who had alanine aminotransferase (ALT) levels $>10$ times the upper limit of normal (ULN); three of these elevations were found to be related to SO spasms. The rate of adverse events and SAEs were slightly higher in females and patients $\geq 65$ years old. Patients without a gallbladder had higher rates of adverse events and SAEs across all treatment arms. Ten patients treated with eluxadoline ( 2 and 8, eluxadoline 75 and $100 \mathrm{mg}$, respectively) experienced SO spasms - most of them occurring within the first week of drug initiation. Most of these patients also presented with elevated aminotransferases, which resolved rapidly after treatment discontinuation. ${ }^{27}$

\section{Abuse potential}

Because eluxadoline is a mu-opioid receptor agonist, there is some concern for its abuse potential and addictive properties. In the posttreatment assessment period of Phase II and III studies, the rate of adverse events related to the abuse potential of the drug was similar across placebo, eluxadoline 75-mg, and eluxadoline 100-mg arms $(8.1 \%, 7.9 \%$, and $9.6 \%$, respectively). Rates of dizziness, somnolence, and euphoric mood were slightly higher in the eluxadoline 100-mg arm $(3.2 \%, 1.1 \%$, and $0.2 \%$, respectively) compared to the placebo $(2.2 \%, 0.3 \%$, and $0 \%$, respectively) and eluxadoline 75 -mg arms $(2.6 \%, 0.1 \%$, and $0 \%$, respectively). A drunk feeling was reported by two patients, each taking 75 and $100 \mathrm{mg}$ eluxadoline $(0.1 \%) .^{21}$

The abuse potential after use of oral and intranasal eluxadoline was studied in a randomized, double-blind, doubledummy, placebo- and active-controlled crossover study. Abuse potential was measured using the Drug Liking Visual Analog Scale (VAS) peak (maximum) effect $\left(\mathrm{E}_{\text {max }}\right)$. Drug Liking VAS $\mathrm{E}_{\max }$ scores did not differ significantly when oral eluxadoline was compared to placebo until much higher doses of eluxadoline were tested (300 and 1,000 mg). Oral and intranasal oxycodone (OXY) $\mathrm{E}_{\max }$ scores were significantly greater than for eluxadoline and placebo. Oral median Drug Liking VAS $\mathrm{E}_{\text {max }}$ scores were higher in both oxycodone arms compared to the three eluxadoline arms (OXY immediate release [IR] $30 \mathrm{mg}$ vs eluxadoline $100 \mathrm{mg}$ : $p<0.0001$; OXY IR $30 \mathrm{mg}$ vs eluxadoline 300 and 1,000 mg: $p<0.01$; OXY IR $60 \mathrm{mg}$ vs eluxadoline 100, 300, and 1,000 mg: $p<0.0001$ ). Intranasal median $\mathrm{E}_{\max }$ scores were higher in both oxycodone arms compared to both eluxadoline arms (OXY IR 15 and $30 \mathrm{mg}$ vs eluxadoline $100 \mathrm{mg}$ : $p<0.0001$; OXY IR 15 and $30 \mathrm{mg}$ vs eluxadoline $200 \mathrm{mg}: p<0.0001)$. Subjects who were assigned to oral or intranasal eluxadoline showed no desire to take the drug again. ${ }^{22}$

Although subjects randomized to therapeutic doses of eluxadoline (100 mg) arms had similar Drug Liking VAS scores compared to placebo, euphoric mood was reported with oral (100 mg: 5 [14.3\%]; $300 \mathrm{mg}: 7$ [19.4\%]; 1,000 mg: 10 [27.8\%]) and intranasal (100 mg: 7 [21.9\%]; $200 \mathrm{mg}: 6$ [18.8\%]) administration of eluxadoline. ${ }^{22}$ There were no subjects who reported euphoric mood after intranasal administration of 
placebo lactose and placebo eluxadoline. Two (5.4\%) subjects reported euphoric mood after taking oral placebo. Although statistical significance was not checked, the raw data shows a larger number of patients who experience euphoric mood after eluxadoline administration, as compared to placebo. ${ }^{30}$

\section{Discussion}

IBS-D is a complex disorder characterized by multiple pathologies making an optimal treatment selection difficult. It may take several trials of different pharmacologic and nonpharmacologic treatment modalities until an effective treatment is found. From a pure efficacy standpoint, antispasmodics and antidepressants have the lowest NNTs: 5 and 4, respectively. Eluxadoline and rifaximin have comparable NNTs (eluxadoline in IBS-3001: $75 \mathrm{mg}$ [15] and $100 \mathrm{mg}$ [13]; eluxadoline in IBS-3002: 75 and $100 \mathrm{mg}$ [8]; rifaximin: 11). While direct comparison of efficacy based on NNT is not possible due to variability in trial design, given eluxadoline's moderate efficacy and unique pharmacology, a subset of IBS-D patients may benefit from a trial of this agent. Its use may be limited by some factors discussed below.

Eluxadoline is contraindicated in patients without a gallbladder, known or suspected biliary duct obstruction, or SO disease; alcoholism, alcohol abuse, alcohol addiction, or drinking more than three alcoholic beverages per day; history of pancreatitis, structural disease of the pancreas; severe hepatic impairment (Child-Pugh Class C); and severe constipation and sequelae from constipation. ${ }^{19}$

Several of these contraindications are quite prevalent conditions in the general US population. For instance, according to the National Institute of Alcohol Abuse and Alcoholism, in $2015,26.9 \%$ of people $\geq 18$ years reported binge drinking (defined as $>4$ drinks for women and $>5$ drinks for men in $\sim 2$ hours) within a month, and $6.2 \%$ reported an alcohol use disorder. ${ }^{31}$ In addition, there are more than 600,000 cholecystectomies performed in the USA each year. ${ }^{32}$ The rate of alcohol consumption and cholecystectomies alone considerably limits the number of patients that can safely take eluxadoline.

Additional information that recently became available through postmarketing reporting is alarming. In March 2017, the FDA published a Drug Safety Communication warning patients and healthcare professionals regarding the risk of eluxadoline and the development of pancreatitis, especially in patients without a gallbladder. In a span of almost 2 years, 120 cases of pancreatitis or death have been reported to the FDA. Of these 120 cases, 76 patients were hospitalized, and two died. Both patients who died did not have a gallbladder. In fact, of the 120 cases that were reported, 68 patients disclosed their gallbladder status. Fifty-six of the 68 patients did not have a gallbladder. ${ }^{33}$ This new information heightens the vital importance of reviewing patient medical and surgical history when considering eluxadoline as a treatment option.

Eluxadoline does not seem to have any significant CYP450-related drug-drug interactions, although the eluxadoline package insert does recommend, as a precautionary measure, to monitor patients for impaired mental or physical abilities when strong CYP inhibitors, such as fluconazole (CYP2C19) and clarithromycin (CYP3A4), are coadministered. OATP1B1 inhibitors, such as cyclosporine, and OAT3 and MRP2 inhibitors, such as probenecid, cause an increase in eluxadoline exposure. ${ }^{19,20}$ Compared to other medications for IBS-D, which may have limited number of drug interactions (eg rifaximin), eluxadoline has several interactions that can be clinically important.

Although the addiction and abuse potential of eluxadoline is low, oral and intranasal eluxadoline seem to cause euphoric mood at slightly higher rates compared to placebo. ${ }^{22}$ It is the authors' opinion that eluxadoline should be used with caution in patients battling opioid addiction. It is important to note that eluxadoline's package insert does not contain such a warning.

An additional important consideration is prescription cost. A 30-day supply of eluxadoline 75 or $100 \mathrm{mg}$ is $\$ 1,255.68 .^{34}$ Insurance coverage is uncertain as there are other pharmacologic and nonpharmacologic options for the management of IBS-D. Unlike loperamide, which is available without a prescription and can be taken on an as needed basis, eluxadoline is recommended to be used twice daily for adequate management of IBS-D symptoms. Requirement for daily chronic use of eluxadoline limits its accessibility to patients who are uninsured or underinsured.

\section{Eluxadoline place in therapy}

In clinical practice, patients who have IBS-D frequently try several over-the-counter options before seeing a healthcare provider. Once a patient seeks medical care for their IBS-D symptoms, eluxadoline or other options can be explored. Selection of the most suitable agent would depend on presenting symptoms, comorbidities, allergies, other medications the patient is currently taking, as well as social and surgical history. If eluxadoline is selected based on the patient's presentation and symptoms, a thorough medical and surgical history should be collected and evaluated to assure no contraindications or interactions exist prior to starting the medication. An in-depth patient education session should also 
be conducted to include, besides the typically provided counseling content, information regarding signs and symptoms of acute pancreatitis, which can present with new or worsening severe abdominal pain that may be accompanied by nausea and vomiting. Worsening abdominal pain and constipation, which can be most pronounced when initiating therapy, should be a trigger for a health provider communication and/or visit. Additionally, patients need to be advised that eluxadoline has interactions with some commonly prescribed drugs used for high cholesterol, respiratory disease, and several others; therefore, starting any new medications should be discussed with their healthcare provider. Potential to develop physical or psychological dependence to eluxadoline should also be addressed and evaluated continuously while the patient is on this medication.

\section{Conclusion}

Eluxadoline's multimodal mechanism of action is certainly promising, given that IBS-D can be caused by several different pathologies. Because of the lack of long-term data and no available treatment algorithm for IBS-D, making a concrete recommendation for eluxadoline's use is difficult. The potential benefits of eluxadoline therapy should be assessed on a case-by-case basis, and this option should be reserved for patients who have not experienced relief with adequate trial of non-pharmacologic and pharmacologic interventions with an established track record of safety.

\section{Acknowledgments}

There are no acknowledgments to report.

\section{Disclosure}

The authors report no conflicts of interest in this work.

\section{References}

1. Longstreth GF, Thompson WG, Chey WD, Houghton LA, Mearin F, Spiller RC. Functional bowel disorders. Gastroenterology. 2006;130(5): 1480-1491.

2. Drossman DA, Camilleri M, Mayer EA, Whitehead WE. AGA technical review on irritable bowel syndrome. Gastroenterology. 2002;123(6): 2108-2131.

3. Canavan C, West J, Card T. The epidemiology of irritable bowel syndrome. Clin Epidemiol. 2014;6:71-80.

4. Su AM, Shih W, Presson AP, Chang L. Characterization of symptoms in irritable bowel syndrome with mixed bowel habit pattern. Neurogastroenterol Motil. 2014;26(1):36-45.

5. Dupont HL. Review article: evidence for the role of gut microbiota in irritable bowel syndrome and its potential influence on therapeutic targets. Aliment Pharmacol Ther. 2014;39(10):1033-1042.

6. Owyang C. Irritable Bowel Syndrome. In: Kasper D, Fauci A, Hauser S, Longo D, Jameson J, Loscalzo J, eds. Harrison's Principles of Internal Medicine. 19th ed. New York: McGraw-Hill; 2014. Available from: http://accesspharmacy.mhmedical.com/content.aspx?bookid=1130\&sectionid=79748082. Accessed June 14, 2017.
7. Ford AC, Moayyedi P, Lacy BE, et al; Task Force on the Management of Functional Bowel Disorders. American college of gastroenterology monograph on the management of irritable bowel syndrome and chronic idiopathic constipation. Am J Gastroenterol. 2014;109(Suppl 1):S2-S26.

8. Weinberg DS, Smalley W, Heidelbaugh JJ, Sultan S; American Gastroenterological Association. American gastroenterological association institute guideline on the pharmacological management of irritable bowel syndrome. Gastroenterology. 2014;147(5):1146-1148.

9. Lucak S, Chang L, Halpert A, Harris LA. Current and emergent pharmacologic treatments for irritable bowel syndrome with diarrhea: evidence-based treatment in practice. Therap Adv Gastroenterol. 2017; 10(2):253-275.

10. Chey WD, Kurlander J, Eswaran S. Irritable bowel syndrome: a clinical review. JAMA. 2015;313(9):949-958.

11. Cash BD, Epstein MS, Shah SM. A novel delivery system of peppermint oil is an effective therapy for irritable bowel syndrome symptoms. Dig Dis Sci. 2016;61(2):560-571.

12. Campanelli CM; American Geriatrics Society 2012 Beers Criteria Update Expert Panel. American Geriatrics Society updated Beers Criteria for potentially inappropriate medication use in older adults. J Am Geriatr Soc. 2013;60(4):616-631.

13. Ford AC, Quigley EM, Lacy BE, et al. Effect of antidepressants and psychological therapies, including hypnotherapy, in irritable bowel syndrome: systematic review and meta-analysis. Am J Gastroenterol. 2014;109(9):1350-1365.

14. Xie C, Tang Y, Wang Y, et al. Efficacy and safety of antidepressants for the treatment of irritable bowel syndrome: a meta-analysis. PLoS One. 2015;10(8):e0127815.

15. Ghoshal UC, Shukla R, Ghoshal U. Small intestinal bacterial overgrowth and irritable bowel syndrome: a bridge between functional organic dichotomy. Gut Liver. 2017;11(2):196-208.

16. Zheng Y, Yu T, Tang Y, et al. Efficacy and safety of 5-hydroxytryptamine 3 receptor antagonists in irritable bowel syndrome: a systematic review and meta-analysis of randomized controlled trials. PLoS One. 2017;12(3):1-21.

17. US Food and Drug Administration. Approved Risk Evaluation and Mitigation Strategies (REMS). Available from: https://www.accessdata. fda.gov/scripts/cder/rems/. Accessed June 5, 2017.

18. Garsed K, Chernova J, Hastings M, et al. A randomised trial of ondansetron for the treatment of irritable bowel syndrome with diarrhoea. Gut. 2014;63(10):1617-1625.

19. Viberzi ${ }^{\circledR}$ (Eluxadoline) Tablets [Prescribing Information]. Irvine, CA: Allergen USA Inc; 2017.

20. Davenport JM, Covington P, Bonifacio L, McIntyre G, Venitz J. Effect of uptake transporters OAT3 and OATP1B1 and efflux transporter MRP2 on the pharmacokinetics of eluxadoline. J Clin Pharmacol. 2015;55(5):534-542.

21. Fant RV, Henningfield JE, Cash BD, Dove LS, Covington PS. Eluxadoline demonstrates a lack of abuse potential in Phase 2 and 3 studies of patients with irritable bowel syndrome with diarrhea. Clin Gastroenterol Hepatol. 2017;15(7):1021-1029.

22. Levy-Cooperman N, McIntyre G, Bonifacio L, et al. Abuse potential and pharmacodynamic characteristics of oral and intranasal eluxadoline, a mixed $\mu$ - and $\kappa$-opioid receptor agonist and $\delta$-opioid receptor antagonist. J Pharmacol Exp Ther. 2016;359(3):471-481.

23. Dove LS, Lembo A, Randall CW, et al. Eluxadoline benefits patients with irritable bowel syndrome with diarrhea in a phase 2 study. Gastroenterology. 2013;145(2):329-338.

24. Lembo AJ, Lacy BE, Zuckerman MJ, et al. Eluxadoline for irritable bowel syndrome with diarrhea. $N$ Engl J Med. 2016;374(3):242-253.

25. Lacy BE, Chey WD, Cash BD, Lembo AJ, Dove LS, Covington PS. Eluxadoline efficacy in IBS-D patients who report prior loperamide use. Am J Gastroenterol. 2017;112(6):924-932.

26. Chey WD, Dove LS, Andrae DA, Covington PS. Early response predicts a sustained response to eluxadoline in patients with irritable bowel syndrome with diarrhoea in two Phase 3 studies. Aliment Pharmacol Ther. 2017;45(10):1319-1328. 
27. Cash BD, Lacy BE, Schoenfeld PS, Dove LS, Covington PS. Safety of eluxadoline in patients with irritable bowel syndrome with diarrhea. Am J Gastroenterol. 2016;112(2):365-374.

28. Gastroenterology. Pharm Lett. 2017;33. Available from: http://pharmacistsletter.therapeuticresearch.com/pl/ArticleDD.aspx?nidchk=1\&c $\mathrm{s}=$ FACULTY $\& \mathrm{~s}=\mathrm{PL} \& \mathrm{pt}=6 \& \mathrm{fpt}=31 \& \mathrm{dd}=330509 \& \mathrm{pb}=\mathrm{PL} \& \mathrm{cat}=4021$. Accessed July 7, 2017.

29. Thoeni RF. The revised a Atlanta classification of acute pancreatitis: its importance for the radiologist and its effect on treatment. Radiology. 2012;262(3):751-764

30. Levy-Cooperman N, McIntyre G, Bonifacio L, et al. Abuse potential and pharmacodynamic characteristics of oral and intranasal eluxadoline, a mixed $\mu$ - and $\kappa$-opioid receptor agonist and $\delta$-opioid receptor antagonist. J Pharmacol Exp Ther. 2016;359(3 Suppl 1):471-481.

31. National Institute on Alcohol Abuse and Alcoholism. Alcohol Facts and Statistics. Available from: https://www.niaaa.nih.gov/alcohol-health/ overview-alcohol-consumption/alcohol-facts-and-statistics. Published 2017. Accessed June 13, 2017.
32. Barnes DS. Gallbladder and Biliary Tract Disease. Cleveland Clinic. Available from: http://www.clevelandclinicmeded.com/medicalpubs/ diseasemanagement/hepatology/gallbladder-biliary-tract-disease/. Published 2010. Accessed June 13, 2017.

33. US Food and Drug Administration. FDA Drug Safety Communication: FDA warns about increased risk of serious pancreatitis with irritable bowel drug Viberzi (eluxadoline) in patients without a gallbladder. Available from: https://www.fda.gov/Drugs/DrugSafety/ucm546154. htm. Published 2017. Accessed June 14, 2017.

34. Eluxadoline. LexiComp. Available from: https://online.lexi.com/lco/ action/doc/retrieve/docid/patch_f/5680923\#fee. Accessed June 14, 2017.

\section{Publish your work in this journal}

Drug Design, Development and Therapy is an international, peerreviewed open-access journal that spans the spectrum of drug design and development through to clinical applications. Clinical outcomes, patient safety, and programs for the development and effective, safe, and sustained use of medicines are the features of the journal, which has also been accepted for indexing on PubMed Central. The manuscript management system is completely online and includes a very quick and fair peer-review system, which is all easy to use. Visit http://www.dovepress.com/testimonials.php to read real quotes from published authors.

Submit your manuscript here: http://www.dovepress.com/drug-design-development-and-therapy-journal 